\title{
Cognitive impairment in depression: a systematic review and meta-analysis
}

Citation for published version (APA):

Rock, P. L., Roiser, J. P., Riedel, W. J., \& Blackwell, A. D. (2014). Cognitive impairment in depression: a systematic review and meta-analysis. Psychological Medicine, 44(10), 2029-2040.

https://doi.org/10.1017/S0033291713002535

Document status and date:

Published: 01/07/2014

DOI:

10.1017/S0033291713002535

Document Version:

Publisher's PDF, also known as Version of record

Document license:

Taverne

Please check the document version of this publication:

- A submitted manuscript is the version of the article upon submission and before peer-review. There can be important differences between the submitted version and the official published version of record.

People interested in the research are advised to contact the author for the final version of the publication, or visit the DOI to the publisher's website.

- The final author version and the galley proof are versions of the publication after peer review.

- The final published version features the final layout of the paper including the volume, issue and page numbers.

Link to publication

\footnotetext{
General rights Owners
rights.

- You may freely distribute the URL identifying the publication in the public portal. please follow below link for the End User Agreement:

www.umlib.nl/taverne-license

Take down policy

If you believe that this document breaches copyright please contact us at:

repository@maastrichtuniversity.nl

providing details and we will investigate your claim.
}

Copyright and moral rights for the publications made accessible in the public portal are retained by the authors and/or other copyright owners and it is a condition of accessing publications that users recognise and abide by the legal requirements associated with these

- Users may download and print one copy of any publication from the public portal for the purpose of private study or research.

- You may not further distribute the material or use it for any profit-making activity or commercial gain

If the publication is distributed under the terms of Article $25 \mathrm{fa}$ of the Dutch Copyright Act, indicated by the "Taverne" license above, 


\title{
Cognitive impairment in depression: a systematic review and meta-analysis
}

\author{
P. L. Rock ${ }^{1,2 *}$, J.P. Roiser ${ }^{3}$, W. J. Riedel ${ }^{1,4,5}$ and A. D. Blackwell ${ }^{1,4}$ \\ ${ }^{1}$ Cambridge Cognition, Bottisham, Cambridge, UK \\ ${ }^{2}$ Department of Psychiatry, University of Oxford, UK \\ ${ }^{3}$ UCL Institute of Cognitive Neuroscience, London, UK \\ ${ }^{4}$ Department of Psychiatry, University of Cambridge, UK \\ ${ }^{5}$ Faculty of Psychology and Neuroscience, Maastricht University, The Netherlands
}

Background. This review aimed to address the question of whether cognitive impairment should be considered a core feature of depression that may be a valuable target for treatment.

\begin{abstract}
Method. We conducted a systematic review and meta-analysis of cognitive function, assessed with a single neuropsychological test battery, the Cambridge Neuropsychological Test Automated Battery (CANTAB), in patients with depression during symptomatic and remitted states. Inclusion of studies comparing patients remitted from depression and controls enabled us to investigate whether cognitive impairment persists beyond episodes of low mood in depression.
\end{abstract}

Results. Our meta-analysis revealed significant moderate cognitive deficits in executive function, memory and attention in patients with depression relative to controls (Cohen's $d$ effect sizes ranging from -0.34 to -0.65 ). Significant moderate deficits in executive function and attention (Cohen's $d$ ranging from -0.52 to -0.61 ) and non-significant small/moderate deficits in memory (Cohen's $d$ ranging from -0.22 to -0.54 ) were found to persist in patients whose depressive symptoms had remitted, indicating that cognitive impairment occurs separately from episodes of low mood in depression.

Conclusions. Both low mood and cognitive impairment are associated with poor psychosocial functioning. Therefore, we argue that remediation of cognitive impairment and alleviation of depressive symptoms each play an important role in improving outcome for patients with depression. In conclusion, this systematic review and metaanalysis demonstrates that cognitive impairment represents a core feature of depression that cannot be considered an epiphenomenon that is entirely secondary to symptoms of low mood and that may be a valuable target for future interventions.

Received 16 June 2013; Revised 16 September 2013; Accepted 17 September 2013; First published online 29 October 2013

Key words: Attention, CANTAB, cognition, depression, executive function, memory.

\section{Introduction}

Cognitive impairment is frequently observed in patients suffering from depression and is associated with poor response to treatment (Potter et al. 2004; Story et al. 2008; Roiser et al. 2012). Impaired cognition has been estimated to occur in around two-thirds of depressed patients (Abas et al. 1990; Butters et al. 2004; Afridi et al. 2011). Impaired ability to think, concentrate or make decisions is a DSM-IV-TR (APA, 2000) diagnostic criterion for major depressive episode. Consistent with this, several systematic reviews have demonstrated cognitive deficits in patients suffering from depression (Burt et al. 1995; Veiel, 1997;

\footnotetext{
* Address for correspondence: P. L. Rock, D.Phil., Cambridge Cognition, Tunbridge Court, Tunbridge Lane, Bottisham, Cambridge CB25 9TU, UK.

(Email: philippa.rock@gmail.com)
}

Zakzanis et al. 1998; Stefanopoulou et al. 2009; Snyder 2013), including first-episode patients (Lee et al. 2012).

Impairments in cognition have been found to persist beyond acute episodes of depression, and between one-third and one-half of remitted depressed patients are thought to be affected by cognitive deficits (Abas et al. 1990; Bhalla et al. 2006; Reppermund et al. 2009). Furthermore, one study revealed that $94 \%$ of patients who had cognitive impairment while depressed continued to experience deficits in cognition when remitted from depression (Bhalla et al. 2006).

To our knowledge, to date, only two groups have reviewed cognitive function in patients remitted from depression (Hasselbalch et al. 2011; Bora et al. 2013). The review by Hasselbalch et al. (2011) included 500 remitted patients (and 472 controls) and revealed impaired cognitive performance in nine of the 11 included studies. Their review also assessed the association between cognitive function and other clinical 
features such as residual depressive symptoms and current medication status. However, drawbacks of this review relate to the large number of different cognitive tests that were used across studies and the lack of implementation of standardized effect sizes to reflect magnitude of impairment. Meanwhile, the review by Bora et al. (2013) included 895 remitted patients (and 997 controls) from 27 studies and, using standardized effect sizes, revealed cognitive deficits in a composite measure of global cognition, in individual cognitive domain composites and in a subset of specific tasks. The review also separately assessed cognitive function in early-onset and late-onset patients and included a meta-regression to uncover the influence of other clinical and demographic factors on cognitive performance. Again, a minor drawback of this review is that task-specific analyses were limited to a subgroup of cognitive tests for which there were sufficient data; therefore, cognitive domain and global cognition meta-analyses necessarily included results from a variety of cognitive tests. A review of the longitudinal course of cognitive function in depression revealed that improvements in mood were most closely related to improvements in verbal memory, verbal fluency and psychomotor speed, whereas attention and executive function remained impaired across treatment (Douglas \& Porter, 2009).

Our aim was to conduct a systematic review and meta-analysis to investigate the degree of cognitive impairment in patients with depression during symptomatic and remitted states, focusing on studies that used a single neuropsychological test battery, the Cambridge Neuropsychological Test Automated Battery (CANTAB). Our rationale for including only CANTAB studies was to enable assessment of a broad range of cognitive domains but with consistent tasks implemented across reviewed studies, thereby ensuring interstudy homogeneity. We predicted that cognitive deficits would be observable in both depressed and remitted states.

\section{Method}

\section{Systematic review}

Studies were identified by searching PubMed and Google Scholar using the following search terms: 'Cambridge neuropsychological test automated battery' or 'CANTAB' and any CANTAB test name (e.g. 'Spatial Span') or its acronym ('SSP') and 'depression' or 'depressed' during the period from 1980 to December 2012. The CANTAB neuropsychological tests included in the search involved the domains of executive function, memory, attention and reaction time, as follows.

\section{Executive function}

(One Touch) Stockings of Cambridge (OTS/SOC; Owen et al. 1990). This task was derived from the Tower of London test and assesses visual planning, reasoning and impulsivity. Outcome measures analysed were the number/percentage correct or number of moves above the minimum [for all problems or difficult (four/five-move) problems].

Spatial Working Memory (SWM; Owen et al. 1995). This self-ordered search task is based on foraging behaviour and assesses working memory and strategy use. Participants search for tokens without returning to previous token locations. Outcome measure analysed was between-search errors.

Intra-Extra Dimensional Set Shift (IED; Rogers et al. 1999). This test of cognitive flexibility, analogous to the Wisconsin Card Sorting Test (WCST), has multiple stages segregating cognitive processes that assess rule learning, rule reversal and attentional set-shifting. Outcome measures analysed were total errors, extradimensional shift errors (adjusted) or stages completed.

Spatial Span (SSP; Kempton et al. 1999). This is a task of spatial short-term memory based on the Corsi blocktapping task. Outcome measure analysed was spatial span.

\section{Memory}

Delayed Matching to Sample (DMS; Robbins et al. 1994). In this test participants remember the visual features of a complex, abstract target stimulus and select it from a choice of four target patterns after a variable delay. Outcome measures analysed were total/percentage correct (for all trials or 12-s delay trials).

Paired Associates Learning (PAL; Sahakian et al. 1988). In this test participants learn the locations of a progressively increasing number of abstract stimuli. Outcome measures analysed were total errors (adjusted) or first trials correct.

Pattern Recognition Memory (PRM; Owen et al. 1995). This is a two-forced-choice test of abstract visual pattern recognition memory. Outcome measures analysed were total/percentage correct.

Spatial Recognition Memory (SRM; Owen et al. 1995). This two-forced-choice discrimination paradigm tests spatial recognition memory. Outcome measures analysed were total/percentage correct. 


\section{Attention}

Rapid Visual Information Processing (RVP; Sahakian et al. 1989). This is a continuous performance test that assesses sustained attention, signal detection and impulsivity. Participants monitor a stream of single digits for three-digit target sequences. Outcome measures analysed were target sensitivity or total hits/omissions.

\section{Reaction time}

Reaction Time (RTI; Sahakian et al. 1993). This is a test of simple and five-choice reaction time. Outcome measure analysed was five-choice reaction time.

\section{Inclusion criteria}

The inclusion criteria for studies were: (1) used DSM or ICD criteria to diagnose major depressive disorder; (2) included a healthy control group; (3) used CANTAB to assess cognitive function in currently depressed patients and/or remitted depressed patients; and (4) reported sufficient data to estimate Cohen's $d$ effect sizes, that is the group mean and either standard deviation or standard error data (and number of subjects in each group) were available for both patients and controls.

Our search revealed 24 studies including 784 currently depressed patients (and 727 controls) and six studies including 168 remitted depressed patients (and 178 controls) that met our inclusion criteria (see Table 1). The criteria for remitted depression varied across studies and are shown in Table 1.

\section{Meta-analysis}

Meta-analysis was performed using Review Manager (RevMan, 2011). For each study, Cohen's $d$ effect sizes (Cohen, 1988) were calculated as the mean difference between test performance scores for patients compared to controls divided by the pooled standard deviation; negative effect sizes reflected deficits compared to controls. Subsequently, for each test, effect sizes were weighted using the inverse variance method within a random-effects model and pooled across all studies with available data. Pooled effect sizes were reported for tests only when data from three or more studies were available. In addition to meta-analyses for currently depressed patients versus controls and remitted depressed patients versus controls, a separate subanalysis was conducted for currently depressed patients who were unmedicated at the time of assessment versus controls. There were insufficient studies of unmedicated remitted depressed patients to include a subanalysis of this population. Influenced by Cohen's convention regarding the magnitude of effect sizes (Cohen, 1988), a Cohen's $d$ effect size in the range $0.2-0.35$ was considered small, in the range $0.35-0.65$ moderate and $>0.65$ large. Statistical inferences were made based upon analysis of $95 \%$ confidence intervals (CIs).

\section{Results}

\section{Profile of cognitive deficits in currently depressed patients}

Cohen's $d$ effect sizes were calculated based on data from 24 studies that used CANTAB tests in 784 currently depressed patients and 727 controls. Fig. 1 shows the weighted, pooled Cohen's $d$ effect sizes for the comparison between depressed patients and healthy controls (black bars), and Table 2 presents detailed meta-analysis results.

Currently depressed patients showed significant moderate deficits compared to healthy controls across the cognitive domains of executive function (Cohen's $d$ ranged from -0.34 to -0.54 ), memory (Cohen's $d$ ranged from -0.41 to -0.50 ) and attention (Cohen's $d$ was -0.65), and there was no significant deficit in reaction time (Cohen's $d$ was -0.07). The non-significant finding for reaction time should be treated with caution because the results seem to have been affected by one study for which depressed patients showed significantly superior performance to controls. Indeed, when this study was excluded, currently depressed patients showed a nearly significant small deficit in reaction time compared to controls $(d=-0.32$, 95\% CIs -0.59 to -0.05). Supplementary Fig. S1 (available online) presents forest plots depicting performance of currently depressed patients relative to controls.

\section{Subanalysis: profile of cognitive deficits in unmedicated currently depressed patients}

Cohen's $d$ effect sizes were calculated based on data from eight studies that used CANTAB tests in 271 currently depressed patients who were unmedicated at the time of assessment and 267 controls. There were sufficient data to calculate weighted, pooled effect sizes for all executive function tasks, all memory tasks, and for the task of attention; insufficient data were available to calculate a weighted, pooled effect size for the reaction time task. Table 2 presents detailed meta-analysis results.

Unmedicated currently depressed patients showed significant moderate deficits compared to healthy controls on one executive function task (SWM; Cohen's $d$ was -0.46), two memory tasks (DMS and PRM; Cohen's $d$ ranged from -0.33 to -0.36$)$ and the attention task (RVP; Cohen's $d$ was -0.59). Although negative Cohen's $d$ effect sizes (ranging from -0.06 to -0.49) were recorded for all remaining tasks, the 
Table 1. Study characteristics and patient demographics for currently depressed and remitted depressed comparisons

\begin{tabular}{|c|c|c|c|c|c|c|c|c|c|}
\hline \multirow{2}{*}{$\begin{array}{l}\text { First } \\
\text { author }\end{array}$} & \multirow[b]{2}{*}{ Year } & \multicolumn{5}{|c|}{ Currently depressed patients } & \multicolumn{2}{|l|}{ Controls } & \multirow[b]{2}{*}{ Notes } \\
\hline & & $n$ (female) & Age (years) & Diagnostic criteria & Depression symptoms & Medication status & $n$ (female) & Age (years) & \\
\hline Beats & 1996 & $24(12)$ & $72.0 \pm 5.9$ & DSM-III-R & $\begin{array}{l}\text { HAMD-x } 29.6 \pm 5.1 \\
\text { MADRS } 40.3 \pm 7.2\end{array}$ & $\begin{array}{l}\text { Twenty-one medicated, three } \\
\text { medication free }\end{array}$ & $15(9)$ & $69.3 \pm 6.6$ & Minimum age of 60 \\
\hline Boeker & 2012 & $28(13)$ & $39.7 \pm 11.4$ & $\begin{array}{l}\text { DSM-x; HAMD-21 } \\
\geqslant 24 ; \text { BDI } \geqslant 24\end{array}$ & $\begin{array}{l}\text { HAMD-21 } 28.5 \pm 7.0 \\
\text { BDI } 25.9 \pm 8.2\end{array}$ & $\begin{array}{l}\text { Nineteen medicated, nine } \\
\text { medication free }\end{array}$ & $28(13)$ & $35.0 \pm 7.4$ & \\
\hline \multirow[t]{3}{*}{ Braw } & 2011 & $25(14)$ & $54.0 \pm 0.9$ & $\begin{array}{l}\text { DSM-IV; } \\
\text { HAMD-17>14 }\end{array}$ & $\begin{array}{l}\text { HAMD-17 } 31.3 \pm 1.3 \\
\text { BDI } 30.8 \pm 1.4\end{array}$ & $\begin{array}{l}\text { All unmedicated for } 1 \text { month prior } \\
\text { to testing }\end{array}$ & $25(17)$ & $54.2 \pm 0.9$ & $\begin{array}{l}\text { Late adulthood group } \\
\text { aged } 46-65\end{array}$ \\
\hline & & $30(16)$ & $35.0 \pm 1.0$ & $\begin{array}{l}\text { DSM-IV; } \\
\text { HAMD-17>14 }\end{array}$ & $\begin{array}{l}\text { HAMD-17 } 32.5 \pm 1.1 ; \\
\text { BDI } 33.5 \pm 1.4\end{array}$ & $\begin{array}{l}\text { All unmedicated for } 1 \text { month prior } \\
\text { to testing }\end{array}$ & $30(16)$ & $34.5 \pm 1.1$ & $\begin{array}{l}\text { Middle adulthood } \\
\text { group aged } 25-45\end{array}$ \\
\hline & & $30(20)$ & $17.1 \pm 0.5$ & $\begin{array}{l}\text { DSM-IV; CDRS } \\
\quad \geqslant 40\end{array}$ & $\begin{array}{l}\text { CDRS-R } 67.5 \pm 2.0 \\
\text { BDI } 32.6 \pm 1.3\end{array}$ & $\begin{array}{l}\text { All unmedicated for } 1 \text { month prior } \\
\text { to testing }\end{array}$ & $30(18)$ & $17.5 \pm 0.6$ & $\begin{array}{l}\text { Young adult group aged } \\
<25\end{array}$ \\
\hline Cannon & 2009 & $18(11)$ & $31 \pm 11$ & DSM-IV & $\begin{array}{l}\text { MADRS } 22 \pm 5.3 \\
\text { IDS-C } 27 \pm 6.5\end{array}$ & $\begin{array}{l}\text { All unmedicated (of whom } \\
11 \text { treatment naïve) }\end{array}$ & $19(11)$ & $31 \pm 8.5$ & Aged 18-55 \\
\hline Elliott & 1996 & $28(19)$ & $49.9 \pm 1.7$ & DSM-III-R & $\begin{array}{l}\text { HAMD-x } 22.4 \pm 0.8 \\
\text { MADRS } 34.0 \pm 1.1\end{array}$ & All medicated & $22(15)$ & $48.1 \pm 1.2$ & Aged 40-70 \\
\hline Elliott & 1997 & $6(1)$ & $34.7(21-48)$ & DSM-IV & $\begin{array}{l}\text { HAMD-x } 23.8 \\
(20-29) ; \text { MADRS } 35.3 \\
(x-39)\end{array}$ & Five medicated, one unmedicated & $6(1)$ & $31.0(18-55)$ & \\
\hline Erickson & 2005 & $20(10)$ & $37.2 \pm 11.9$ & DSM-IV & MADRS $25.4 \pm 7.1$ & $\begin{array}{l}\text { All unmedicated for } 3 \text { weeks } \\
\text { prior to testing } \\
\text { (of whom four medication naïve) }\end{array}$ & $\begin{array}{l}\text { Matched } \\
\text { (not stated) }\end{array}$ & $\begin{array}{l}\text { Matched } \\
\text { (not stated) }\end{array}$ & $\begin{array}{l}\text { All had illness onset } \\
\text { before age } 40\end{array}$ \\
\hline Grant & 2001 & 48 & $39.0 \pm 10.4$ & DSM-IV & HAMD-17 16.7 \pm 5.4 & $\begin{array}{l}\text { All unmedicated patients for } \\
28 \text { days prior to testing }\end{array}$ & 31 & $40.2 \pm 9.7$ & $\begin{array}{l}\text { Demographics are for a } \\
\text { larger sample from } \\
\text { which these subjects } \\
\text { were drawn }\end{array}$ \\
\hline Heinzel & 2010 & $20(11)$ & $40.0 \pm 9.9$ & $\begin{array}{l}\text { DSM-IV; } \\
\text { HAMD-21 } \geqslant 24\end{array}$ & $\begin{array}{l}\text { HAMD-21 } 33.1 \pm 7.1 \\
\text { BDI } 29.9 \pm 4.9\end{array}$ & $\begin{array}{l}\text { All unmedicated for } 1 \text { week } \\
\text { prior to testing }\end{array}$ & $29(21)$ & $35.3 \pm 7.3$ & \\
\hline Kyte & 2005 & $30(18)$ & $15.3 \pm 2.5$ & K-SADS-PL & HAMD-x $10.9 \pm 6.8$ & $\begin{array}{l}\text { Medicated and unmedicated } \\
\text { adolescents }\end{array}$ & $49(29)$ & $15.2 \pm 2.1$ & \\
\hline Lyche & 2010 & $37(23)$ & $44.2 \pm 12.3$ & DSM-IV & BDI $21.4 \pm 11.1$ & $\begin{array}{l}\text { Thirteen medicated, } \\
24 \text { unmedicated }\end{array}$ & $91(63)$ & $35.8 \pm 12.0$ & \\
\hline Maalouf & 2010 & $20(16)$ & $34.2 \pm 9.4$ & $\begin{array}{l}\text { DSM-IV; } \\
\text { HAMD-25 } \geqslant 17\end{array}$ & HAMD-5 $24.8 \pm 5.8$ & All medicated & $28(19)$ & $31.9 \pm 9.4$ & \\
\hline Maalouf & 2011 & $20(17)$ & $15.3 \pm 1.6$ & $\begin{array}{l}\text { DSM-IV; } \\
\text { K-SADS-PL }\end{array}$ & CDRS $58.6 \pm 10.9$ & $\begin{array}{l}\text { Thirteen medicated, } \\
\text { seven unmedicated }\end{array}$ & $17(9)$ & $15.2 \pm 1.8$ & \\
\hline Matthews & 2008 & $14(14)$ & $14.5 \pm 1.2$ & ICD-10; CAPA-C & MFQ $41.3 \pm 10.4$ & All medication naïve & $14(14)$ & $14.4 \pm 1.0$ & \\
\hline Michopoulos & 2008 & $40(40)$ & $52.7 \pm 10.8$ & DSM-IV-TR & HAMD-17 $20.0 \pm 4.0$ & All medicated & $20(20)$ & $49.8 \pm 12.7$ & \\
\hline
\end{tabular}




\begin{tabular}{|c|c|c|c|c|c|c|c|c|c|}
\hline Michopoulos & 2006 & $\begin{array}{l}11(11) \\
11(11)\end{array}$ & $\begin{array}{l}50.9 \pm 10.5 \\
47.8 \pm 12.3\end{array}$ & $\begin{array}{l}\text { DSM-IV } \\
\text { DSM-IV }\end{array}$ & $\begin{array}{l}\text { HAMD-x } 20.8 \pm 3.1 \\
\text { HAMD-x } 18.7 \pm 4.2\end{array}$ & $\begin{array}{l}\text { All medicated } \\
\text { All medicated }\end{array}$ & $11(11)$ & $52.8 \pm 14.1$ & $\begin{array}{l}\text { Melancholic subgroup } \\
\text { Non-melancholic } \\
\text { subgroup }\end{array}$ \\
\hline Murphy & 2003 & $27(14)$ & $38.9 \pm 9.7$ & DSM-IV & $\begin{array}{c}\text { HAMD-x } 23.6 \pm 4.2 \\
\text { MADRS } 34.3 \pm 5.4\end{array}$ & $\begin{array}{l}\text { Twenty-six medicated, one } \\
\text { unmedicated }\end{array}$ & $23(12)$ & $39.1 \pm 10.8$ & \\
\hline O'Brien & 2004 & $61(48)$ & $73.9 \pm 6.7$ & $\begin{array}{l}\text { DSM-IV; MADRS } \\
\geqslant 20\end{array}$ & MADRS $30.7 \pm 7.1$ & $\begin{array}{l}\text { Mostly medicated (numbers } \\
\text { not stated) }\end{array}$ & $40(30)$ & $73.3 \pm 6.7$ & Aged over 60 \\
\hline Porter & 2003 & $44(29)$ & $32.9 \pm 10.6$ & DSM-IV & $\begin{array}{l}\text { HAMD-17 21.1 } \pm 4.4 ; \\
\text { MADRS 28.9 } \pm 5.5 ; \\
\text { BDI } 27.9 \pm 10.2\end{array}$ & $\begin{array}{l}\text { All unmedicated (of whom } \\
26 \text { medication naïve) } \\
\text { for } 6 \text { weeks prior to testing }\end{array}$ & $44(29)$ & $32.3 \pm 11.4$ & \\
\hline Purcell & 1997 & $20(12)$ & $37.5(18-52)$ & DSM-IV & HAMD-24 22.6 \pm 5.6 & $\begin{array}{l}\text { Twelve medicated, eight } \\
\text { unmedicated for }\end{array}$ & $20(12)$ & $37.2(21-60)$ & \\
\hline Reppermund & 2009 & $53(28)$ & $43.5 \pm 8.0$ & DSM-IV & HAMD-x $25.1 \pm 5.1$ & $\begin{array}{l}2 \text { months prior to testing } \\
\text { Fifty medicated, three } \\
\text { unmedicated }\end{array}$ & $13(7)$ & $46.4 \pm 9.5$ & \\
\hline Swainson & 2001 & 37 & $60.8 \pm 8.6$ & DSM-IV & HAMD-x $21.4 \pm 6.2$ & Not stated & 39 & $64.4 \pm 8.5$ & \\
\hline Sweeney & 2000 & $58(39)$ & $32.3 \pm 9.1$ & DSM-IV & HAMD-17 21.6 \pm 4.3 & Medicated patients & $51(39)$ & $36.3 \pm 9.7$ & \\
\hline $\begin{array}{l}\text { Taylor } \\
\text { Tavares }\end{array}$ & 2007 & $22(17)$ & $38.6 \pm 8.1$ & DSM-IV & MADRS $25.5 \pm 7.5$ & Unmedicated patients & $25(18)$ & $34.8 \pm 8.8$ & \\
\hline Tsaltas & 2010 & $\begin{array}{l}15(15) \\
15(15)\end{array}$ & $\begin{array}{l}47.8 \pm 11.7 \\
48.5 \pm 11.2\end{array}$ & $\begin{array}{l}\text { DSM-IV-TR } \\
\text { DSM-IV-TR }\end{array}$ & $\begin{array}{l}\text { HAMD-24 27.6 } \pm 5.6 \\
\text { HAMD-24 31.9 } \pm 6.5\end{array}$ & $\begin{array}{l}\text { All medicated } \\
\text { All medicated }\end{array}$ & $15(15)$ & $49.3 \pm 11.6$ & $\begin{array}{l}\text { Non-referred subgroup } \\
\text { Referred subgroup }\end{array}$ \\
\hline
\end{tabular}

Remitted patients

\begin{tabular}{|c|c|c|c|c|c|c|c|c|c|c|}
\hline \multirow[b]{2}{*}{$\begin{array}{l}\text { First } \\
\text { author }\end{array}$} & \multirow[b]{2}{*}{ Year } & & & & & & & \multicolumn{2}{|l|}{ Controls } & \multirow[b]{2}{*}{ Notes } \\
\hline & & $n$ (female) & Age (years) & Diagnostic criteria & Euthymia definition & $\begin{array}{l}\text { Depression } \\
\text { symptoms }\end{array}$ & $\begin{array}{l}\text { Medication } \\
\text { status }\end{array}$ & $n$ (female) & Age (years) & \\
\hline Beats & 1996 & $19(10)$ & $73.6 \pm 5.4$ & DSM-III-R & MADRS $<10$ & $\begin{array}{c}\text { HAM-D } \\
4.7 \pm 2.6 ; \\
\text { MADRS } \\
6.5 \pm 4.5\end{array}$ & $\begin{array}{l}\text { Mostly } \\
\text { medicated }\end{array}$ & $15(9)$ & $69.3 \pm 6.6$ & \\
\hline $\begin{array}{l}\text { Clark } \\
\text { Clark }\end{array}$ & $\begin{array}{l}2005 a \\
2005 b\end{array}$ & $15(11)$ & $45.2 \pm 10.9$ & DSM-IV & HAMD-x $<9$ & $\begin{array}{c}\text { HAMD-x } \\
2.1 \pm 2.9\end{array}$ & $\begin{array}{l}\text { Six medicated, } \\
\text { nine } \\
\text { unmedicated }\end{array}$ & $46(23)$ & $39.2 \pm 12.2$ & \\
\hline $\begin{array}{l}\text { Herrera- } \\
\text { Guzman }\end{array}$ & 2010 & 60 & $20-50$ & DSM-IV & HAMD-17 <6 & $\begin{array}{l}\text { HAMD-17 } \\
0.7 \pm 0.2\end{array}$ & All unmedicated & 37 & $20-50$ & \\
\hline Maalouf & 2011 & $20(15)$ & $15.4 \pm 1.3$ & $\begin{array}{l}\text { DSM-IV; } \\
\text { K-SADS-PL }\end{array}$ & CDRS $\leqslant 28$ & $\begin{array}{l}\text { CDRS } 23.7 \\
\pm 10.9\end{array}$ & $\begin{array}{l}\text { Thirteen } \\
\text { medicated, } \\
\text { seven } \\
\text { unmedicated }\end{array}$ & $17(9)$ & $15.2 \pm 1.8$ & \\
\hline
\end{tabular}




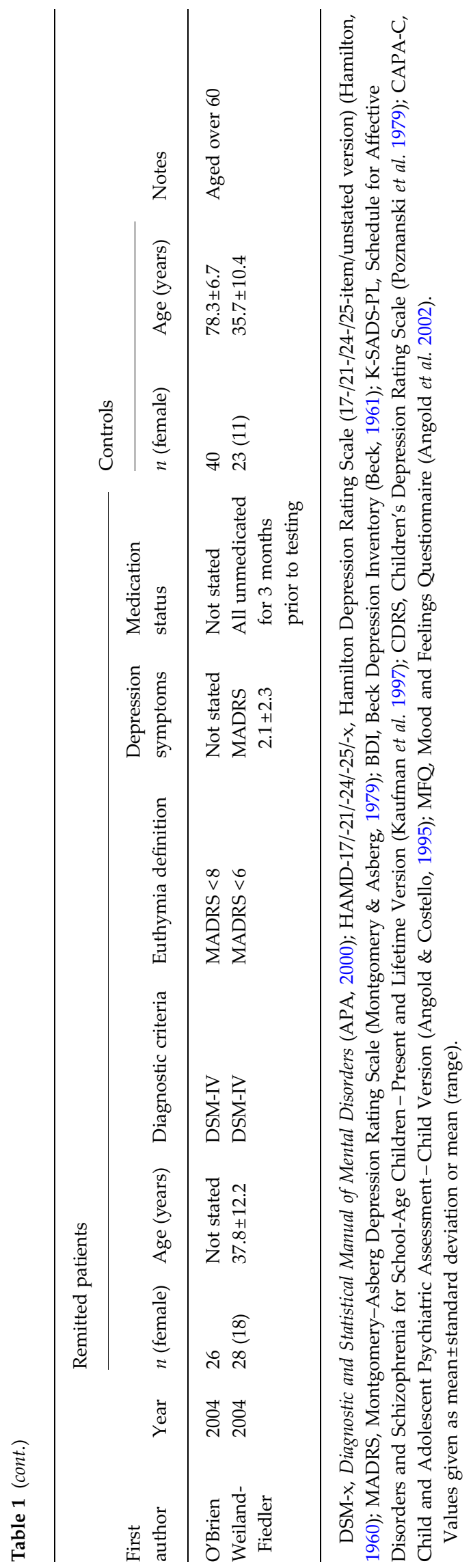

95\% CIs crossed zero in all cases. Supplementary Fig. S2 presents forest plots depicting performance of unmedicated currently depressed patients relative to controls.

\section{Profile of cognitive deficits in remitted depressed patients}

Cohen's $d$ effect sizes were based on data from six studies that used CANTAB tests in 168 remitted depressed patients and 178 controls. There were sufficient data to calculate weighted, pooled effect sizes for three (out of four) tasks in the domain of executive function, two (out of four) tasks in the domain of memory, and for the task of attention; insufficient data were available to calculate a weighted, pooled effect size for the reaction time task. Fig. 1 shows the weighted, pooled Cohen's $d$ effect sizes for the comparison between depressed patients and healthy controls (grey bars), and Table 2 presents detailed meta-analysis results.

Patients remitted from depression showed significant moderate deficits compared to healthy controls across the cognitive domains of executive function (Cohen's $d$ ranged from -0.53 to -0.61 ) and attention (Cohen's $d$ was -0.52). There was a tendency towards moderate deficits in the domain of memory (Cohen's $d$ ranged from -0.22 to -0.54 ). Although the $95 \%$ CIs crossed zero in both cases, they only just crossed zero for PRM (95\% CIs were from -1.08 to 0.01 ). Supplementary Fig. S3 presents forest plots depicting performance of currently depressed patients relative to controls.

\section{Discussion}

Our systematic review and meta-analysis revealed that impairments in cognitive function, assessed with a single neuropsychological test battery (CANTAB), were exhibited by currently depressed patients and by patients remitted from depression. Current depression was associated with significant moderate deficits across all tasks within the domains of executive function, memory and attention, with the exception of the SSP task of executive function, for which there was a tendency towards a moderate deficit. Although the systematic review and meta-analysis revealed no reaction time deficit in currently depressed patients, exploratory reanalysis excluding one anomalous study (in which depressed patients showed significantly superior performance relative to controls) revealed a tendency towards a small deficit in reaction time. Analysis of only unmedicated currently depressed patients showed a significant moderate deficit in the domain of attention and significant small and moderate deficits in some, but not all, tasks within the 


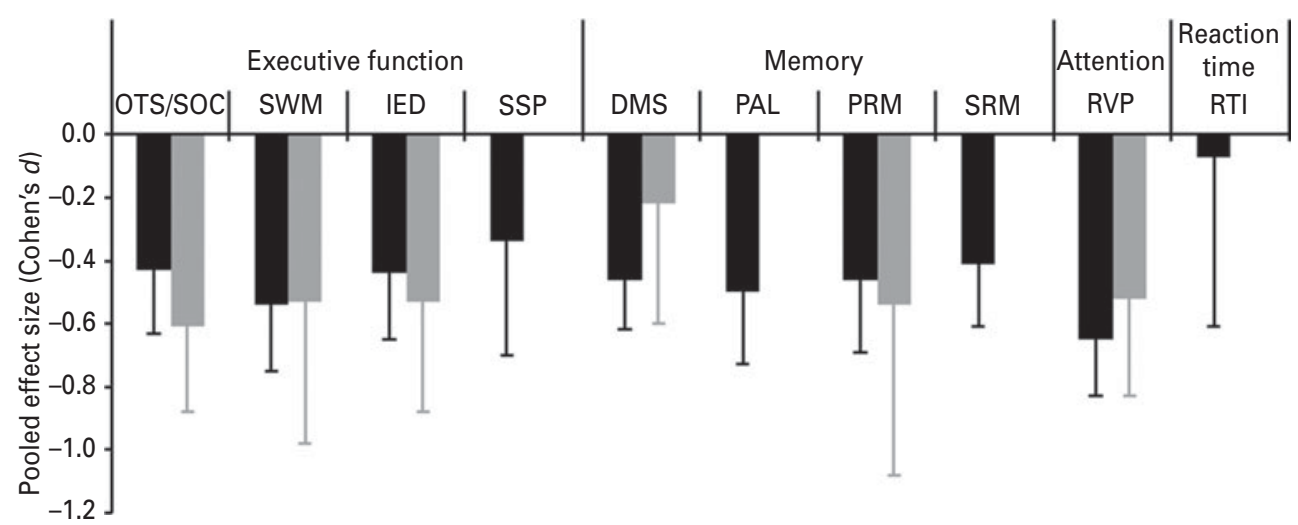

Fig. 1. Pooled, weighted Cohen's $d$ effect sizes reflecting the performance of currently depressed patients (black bars) and remitted depressed patients (grey bars) compared to healthy controls on tasks of executive function [OTS/SOC, (One Touch) Stockings of Cambridge; SWM, Spatial Working Memory; IED, Intra-Extra Dimensional Set Shift; SSP, Spatial Span], memory (DMS, Delayed Matching to Sample; PAL, Paired Associates Learning; PRM, Pattern Recognition Memory; SRM, Spatial Recognition Memory), attention (RVP, Rapid Visual Information Processing) and reaction time (RTI, Reaction Time). Error bars represent $95 \%$ confidence intervals (CIs).

domains of executive function and memory. Meanwhile, remitted depressed patients showed significant moderate deficits within the domains of executive function and attention. However, in the domain of memory, remitted depressed patients showed only a tendency towards small/moderate deficits. In summary, our systematic review and meta-analysis demonstrated that cognitive impairment, particularly affecting the domains of executive function and attention, is a core feature of depression that persists during remission in the absence of clinically relevant symptoms of low mood.

The present systematic review and meta-analysis included only studies that had used CANTAB tasks to assess cognitive function in symptomatic or remitted depressed patients relative to controls. To our knowledge, this is the first systematic review and metaanalysis that has focused on studies using a single neuropsychological test battery. The magnitudes of cognitive deficits recorded in the current investigation are broadly in line with those that have been recorded previously. However, our finding of a non-significant deficit in reaction time in currently depressed patients relative to controls contrasted notably with the literature. Nevertheless, following exclusion of one anomalous result, a tendency towards a small deficit on the RTI task was recorded, and the size of this deficit (Cohen's $d=0.32$ ) was similar to the deficit recorded on the psychomotor speed composite (Cohen's $d=0.33$ ) in the Snyder (2012) meta-analysis.

Impaired cognitive functioning has been linked with poor response to antidepressant treatment (Potter et al. 2004; Story et al. 2008). However, the potential clinical relevance of cognitive deficits in depression also depends upon their impact on psychosocial functioning.
Impaired psychosocial functioning is a core feature of depression (Weissman et al. 2010). It persists in up to $60 \%$ of individuals with depression even after mood symptoms of depression have remitted (Jaeger et al. 2006), indicating that severity of depressive symptoms cannot fully account for impaired functional ability. For example, patients with subsyndromal depressive symptoms have been found to manifest similar levels of psychosocial dysfunction to those of patients with clinically relevant symptoms (Judd et al. 1996). One possible explanation is that persisting cognitive impairments may contribute to poor quality of life and psychosocial functioning in patients whose depressive symptoms have remitted. In support of this, psychosocial functioning has been shown to be associated with performance on measures of attention, executive function, paired associates learning and visuospatial ability in depression (Jaeger et al. 2006). Importantly, the association between cognitive deficits and poor psychosocial functioning has been shown to remain significant even when taking into account residual, subclinical depressive symptoms (Jaeger et al. 2006).

Another study revealed that severity of cognitive impairment and severity of low mood associate independently with different measures of psychosocial functioning (McCall \& Dunn, 2003). Furthermore, in bipolar disorder, psychosocial functioning has been shown to be predicted by both cognition and residual depressive symptoms (Mur et al. 2009; Solé et al. 2012).

Overall, these findings suggest that remediation of cognitive impairment and alleviation of depressive symptoms may both be involved in improving psychosocial functioning in depression. We therefore argue that cognitive impairment in depression is clinically relevant and may be a valuable target for intervention. 
Table 2. Meta-analysis results

\begin{tabular}{|c|c|c|c|c|c|c|c|c|c|}
\hline Task & No. patients & No. controls & No. studies & $d$ & $95 \% \mathrm{CI}$ & Z & $p$ & $Q$ & $I^{2}(\%)$ \\
\hline \multicolumn{10}{|c|}{ Currently depressed patients } \\
\hline OTS/SOC & 557 & 484 & 16 & -0.43 & -0.63 to -0.24 & 4.32 & $<0.0001$ & 43.33 & 56 \\
\hline SWM & 567 & 521 & 15 & -0.54 & -0.75 to -0.33 & 4.98 & $<0.00001$ & 43.92 & 64 \\
\hline IED & 578 & 566 & 16 & -0.44 & -0.65 to -0.23 & 4.07 & $<0.0001$ & 52.97 & 64 \\
\hline SSP & 273 & 217 & 8 & -0.34 & -0.70 to 0.01 & 1.92 & 0.06 & 24.19 & 71 \\
\hline DMS & 423 & 342 & 12 & -0.46 & -0.62 to -0.29 & 5.37 & $<0.00001$ & 13.52 & 19 \\
\hline PAL & 321 & 279 & 9 & -0.50 & -0.73 to -0.26 & 4.17 & $<0.0001$ & 18.43 & 46 \\
\hline PRM & 402 & 347 & 12 & -0.46 & -0.69 to -0.23 & 3.89 & 0.0001 & 25.55 & 57 \\
\hline SRM & 445 & 371 & 13 & -0.41 & -0.61 to -0.22 & 4.19 & $<0.0001$ & 24.38 & 43 \\
\hline RVP & 228 & 236 & 7 & -0.65 & -0.83 to -0.46 & 6.75 & $<0.00001$ & 3.90 & 0 \\
\hline RTI & 157 & 135 & 4 & -0.07 & -0.61 to 0.46 & 0.27 & 0.79 & 14.33 & 79 \\
\hline \multicolumn{10}{|c|}{ Unmedicated currently depressed patients } \\
\hline OTS/SOC & 191 & 174 & 4 & -0.28 & -0.68 to 0.11 & 1.40 & 0.16 & 17.21 & 71 \\
\hline SWM & 231 & 218 & 6 & -0.46 & -0.84 to -0.09 & 2.43 & 0.02 & 25.85 & 73 \\
\hline IED & 171 & 166 & 4 & -0.09 & -0.46 to 0.28 & 0.49 & 0.62 & 14.00 & 64 \\
\hline SSP & 82 & 69 & 3 & -0.06 & -0.66 to 0.54 & 0.20 & 0.84 & 6.18 & 68 \\
\hline DMS & 126 & 112 & 4 & -0.36 & -0.62 to -0.10 & 2.71 & 0.007 & 2.67 & 0 \\
\hline PAL & 106 & 89 & 3 & -0.49 & -1.22 to 0.23 & 1.33 & 0.18 & 11.02 & 82 \\
\hline PRM & 146 & 132 & 5 & -0.33 & -0.61 to -0.04 & 2.23 & 0.03 & 5.42 & 26 \\
\hline SRM & 125 & 112 & 4 & -0.29 & -0.75 to 0.17 & 1.22 & 0.22 & 8.62 & 65 \\
\hline RVP & 123 & 124 & 3 & -0.59 & -0.84 to -0.33 & 4.50 & $<0.00001$ & 1.38 & 0 \\
\hline \multicolumn{10}{|c|}{ Remitted depressed patients } \\
\hline OTS/SOC & 125 & 109 & 4 & -0.61 & -0.88 to -0.34 & 4.47 & $<0.00001$ & 2.80 & 0 \\
\hline SWM & 114 & 100 & 3 & -0.53 & -0.98 to -0.07 & 2.28 & 0.02 & 5.00 & 60 \\
\hline IED & 62 & 84 & 3 & -0.53 & -0.88 to -0.18 & 2.95 & 0.003 & 1.51 & 0 \\
\hline DMS & 74 & 80 & 3 & -0.22 & -0.60 to 0.15 & 1.16 & 0.24 & 2.69 & 26 \\
\hline PRM & 73 & 78 & 3 & -0.54 & -1.08 to 0.01 & 1.92 & 0.05 & 5.24 & 62 \\
\hline RVP & 123 & 123 & 4 & -0.52 & -0.83 to -0.21 & 3.31 & 0.0009 & 3.87 & 22 \\
\hline
\end{tabular}

$d$, Weighted, pooled Cohen's $d$ effect size; CI, confidence interval; $Q$, heterogeneity; $I^{2}$, percentage of total variability due to heterogeneity; OTS/SOC, (One Touch) Stockings of Cambridge; SWM, Spatial Working Memory; IED, Intra-Extra Dimensional Set Shift; SSP, Spatial Span; DMS, Delayed Matching to Sample; PAL, Paired Associates Learning; PRM, Pattern Recognition Memory; SRM, Spatial Recognition Memory; RVP, Rapid Visual Information Processing; RTI, Reaction Time.

Although there are relatively few published studies assessing the cognitive enhancing effects of pharmacological treatments in depression, one potential augmentation therapy is the wakefulness-promoting agent modafinil. Indeed, 4-week adjunctive treatment with modafinil was shown to improve performance on a task of executive function in currently depressed patients with only partial response to antidepressant therapy (DeBattista et al. 2004). However, further research is required to delineate coincidental improvements in mood and fatigue from true improvements in cognitive function.

\section{Limitations}

One limitation of the current systematic review and meta-analysis relates to lack of assessment of the association between cognitive deficits and depressive symptoms. The importance of consideration of this association was highlighted in a meta-analysis that revealed that severity of depressive symptoms correlated significantly with impairment across domains of cognition including executive function, episodic memory and processing speed (McDermott \& Ebmeier, 2009). However, only a small portion (at most around $10 \%$ ) of the variability in cognitive function is accounted for by variability in depressive symptom severity (McDermott \& Ebmeier, 2009). Therefore, there remains considerable separation between symptoms of depressive mood and cognitive impairment in patients suffering from depression, indicating that cognitive impairment cannot be considered entirely as a secondary feature of low mood in depression. Overall, although there is some evidence of an association between depressive symptomatology and cognitive function, this association does not account for the majority 
of variability in cognitive performance in depressed patients.

A further limitation of this study relates to most patients in the included studies being medicated. However, our subanalysis demonstrated significant cognitive deficits in unmedicated currently depressed patients on the SWM, DMS, PRM and RVP tasks, which span the domains of executive function, memory and attention. These findings support the idea that cognitive impairment is at least in part separable from medication effects in currently depressed patients.

The final limitation relates to the range of criteria used to define remission from depression within the remitted samples. Therefore, it is possible that our results may have been affected by the presence of low levels of persisting depressive symptoms in the remitted depressed group.

\section{Conclusions}

This review has demonstrated that cognitive impairment across the domains of executive function and attention, and to an extent memory, represents a core and clinically relevant feature of depression that persists beyond symptoms of low mood. Cognitive impairment is exhibited by depressed patients during current and remitted states, including in unmedicated samples. Previous research has demonstrated that cognitive impairment cannot be fully accounted for by severity of depressive symptoms and, along with symptoms of low mood, is associated with poor psychosocial function. We argue that cognitive impairment may represent a valuable target for new therapies for depression because remediation of cognitive impairment in addition to depressive symptoms will be important in improving functional outcome for patients with depression.

\section{Supplementary material}

For supplementary material accompanying this paper visit http://dx.doi.org/10.1017/S0033291713002535.

\section{Declaration of Interest}

Drs Rock, Riedel and Blackwell are full-time employees of Cambridge Cognition, and Dr Blackwell holds shares in Cambridge Cognition. Dr Roiser is a paid consultant for Cambridge Cognition.

\section{References}

Abas M, Sahakian BJ, Levy R (1990). Neuropsychological deficits and CT scan changes in elderly depressives. Psychological Medicine 20, 507-520.
Afridi M, Hina M, Qureshi I, Hussein M (2011). Cognitive disturbance comparison among drug-naïve depressed cases and healthy controls. Journal of the College of Physicians and Surgeons-Pakistan 21, 351-355.

Angold A, Costello EJ (1995). A test-retest reliability study of child-reported psychiatric symptoms and diagnoses using the Child and Adolescent Psychiatric Assessment (CAPA-C). Psychological Medicine 25, 755-762.

Angold A, Erkanli A, Silberg J, Eaves L, Costello EJ (2002). Depression scale scores in 8-17-year-olds: effects of age and gender. Journal of Child Psychology and Psychiatry, and Allied Disciplines 43, 1052-1063.

APA (2000). Diagnostic and Statistical Manual of Mental Disorders - Text Revision. American Psychiatric Association Washington, DC.

Beats BC, Sahakian BJ, Levy R (1996). Cognitive performance in tests sensitive to frontal lobe dysfunction in the elderly depressed. Psychological Medicine 26, 591-603.

Beck A (1961). A systematic investigation of depression. Comprehensive Psychiatry 2, 163-170.

Bhalla RK, Butters MA, Mulsant BH, Begley AE, Zmuda MD, Schoderbek B, Pollock BG, Reynolds CF 3rd, Becker JT (2006). Persistence of neuropsychologic deficits in the remitted state of late-life depression. American Journal of Geriatric Psychiatry 14, 419-427.

Boeker H, Schulze J, Richter A, Nikisch G, Schuepbach D, Grimm S (2012). Sustained cognitive impairments after clinical recovery of severe depression. Journal of Nervous and Mental Disease 200, 773-776.

Bora E, Harrison BJ, Yücel M, Pantelis C (2013). Cognitive impairment in euthymic major depressive disorder: a meta-analysis. Psychological Medicine 43, 2017-2026.

Braw Y, Aviram S, Bloch Y, Levkovitz Y (2011). The effect of age on frontal lobe related cognitive functions of unmedicated depressed patients. Journal of Affective Disorders 129, 342-347.

Burt DB, Zembar MJ, Niederehe G (1995). Depression and memory impairment: a meta-analysis of the association, its pattern, and specificity. Psychological Bulletin 117, 285-305.

Butters MA, Whyte EM, Nebes RD, Begley AE, Dew MA, Mulsant BH, Zmuda MD, Bhalla R, Meltzer CC, Pollock BG, Reynolds CF 3rd, Becker JT (2004). The nature and determinants of neuropsychological functioning in late-life depression. Archives of General Psychiatry 61, 587-595.

Cannon DM, Klaver JM, Peck SA, Rallis-Voak D, Erickson K, Drevets WC (2009). Dopamine type-1 receptor binding in major depressive disorder assessed using positron emission tomography and [11C]NNC-112. Neuropsychopharmacology 34, 1277-1287.

Clark L, Kempton MJ, Scarnà A, Grasby PM, Goodwin GM (2005a). Sustained attention-deficit confirmed in euthymic bipolar disorder but not in first-degree relatives of bipolar patients or euthymic unipolar depression. Biological Psychiatry 57, 183-187.

Clark L, Sarna A, Goodwin GM (2005b). Impairment of executive function but not memory in first-degree relatives of patients with bipolar I disorder and in euthymic patients 
with unipolar depression. Journal of Medical Genetics 162, 1980-1982.

Cohen J (1988). Statistical Power Analysis for the Behavioral Sciences, 2nd edn. Lawrence Erlbaum Associates: Mahwah, NJ.

DeBattista C, Lembke A, Solvason HB, Ghebremichael R, Poirier J (2004). A prospective trial of modafinil as an adjunctive treatment of major depression. Journal of Clinical Psychopharmacology 24, 87-90.

Douglas KM, Porter RJ (2009). Longitudinal assessment of neuropsychological function in major depression. Australian and New Zealand Journal of Psychiatry 43, 1105-1017.

Elliott R, Baker SC, Rogers RD, O'Leary DA, Paykel ES, Frith CD, Dolan RJ, Sahakian BJ (1997). Prefrontal dysfunction in depressed patients performing a complex planning task: a study using positron emission tomography. Psychological Medicine 27, 931-942.

Elliott R, Sahakian BJ, McKay AP, Herrod JJ, Robbins TW, Paykel ES (1996). Neuropsychological impairments in unipolar depression: the influence of perceived failure on subsequent performance. Psychological Medicine 26, 975-989.

Erickson K, Drevets WC, Clark L, Cannon DM, Bain EE, Zarate CA Jr., Charney DS, Sahakian BJ (2005). Mood-congruent bias in affective go/no-go performance of unmedicated patients with major depressive disorder. American Journal of Psychiatry 162, 2171-2173.

Grant MM, Thase ME, Sweeney JA (2001). Cognitive disturbance in outpatient depressed younger adults: evidence of modest impairment. Biological Psychiatry 50, 35-43.

Hamilton M (1960). A rating scale for depression. Journal of Neurology, Neurosurgery and Psychiatry 23, 56-62.

Hasselbalch BJ, Knorr U, Kessing LV (2011). Cognitive impairment in the remitted state of unipolar depressive disorder: a systematic review. Journal of Affective Disorders 134, 20-31.

Heinzel A, Northoff G, Boeker H, Boesiger P, Grimm S (2010). Emotional processing and executive functions in major depressive disorder: dorsal prefrontal activity correlates with performance in the intra-extra dimensional set shift. Acta Neuropsychiatrica 22, 269-279.

Herrera-Guzmán I, Gudayol-Ferré E, Herrera-Abarca JE, Herrera-Guzmán D, Montelongo-Pedraza $P$, Padrós Blázquez F, Peró-Cebollero M, Guàrdia-Olmos J (2010).

Major depressive disorder in recovery and neuropsychological functioning: effects of selective serotonin reuptake inhibitor and dual inhibitor depression treatments on residual cognitive deficits in patients with major depressive disorder in recovery. Journal of Affective Disorders 123, 341-350.

Jaeger J, Berns S, Uzelac S, Davis-Conway S (2006). Neurocognitive deficits and disability in major depressive disorder. Psychiatry Research 145, 39-48.

Judd LL, Paulus MP, Wells KB, Rapaport MH (1996). Socioeconomic burden of subsyndromal depressive symptoms and major depression in a sample of the general population. American Journal of Psychiatry 153, 1411-1417.

Kaufman J, Birmaher B, Brent D, Rao U, Flynn C, Moreci P, Williamson D, Ryan N (1997). Schedule for Affective Disorders and Schizophrenia for School-Age Children-Present and Lifetime Version (K-SADS-PL): initial reliability and validity data. Journal of the American Academy of Child and Adolescent Psychiatry 36, 980-988.

Kempton S, Vance A, Maruff P, Luk E, Costin J, Pantelis C (1999). Executive function and attention deficit hyperactivity disorder: stimulant medication and better executive function performance in children. Psychological Medicine 29, 527-538.

Kyte A, Goodyer IM, Sahakian BJ (2005). Selected executive skills in adolescents with recent first episode major depression. Journal of Child Psychology and Psychiatry 9, 995-1005.

Lee RSC, Hermens DF, Porter MA, Redoblado-Hodge MA (2012). A meta-analysis of cognitive deficits in first-episode major depressive disorder. Journal of Affective Disorders 140, 113-124.

Lyche P, Jonassen R, Stiles TC, Ulleberg P, Landrø NI (2010). Cognitive control functions in unipolar major depression with and without co-morbid anxiety disorder. Frontiers in Psychiatry 1, 149.

Maalouf FT, Brent D, Clark L, Tavitian L, McHugh RM, Sahakian BJ, Phillips ML (2011). Neurocognitive impairment in adolescent major depressive disorder: state vs. trait illness markers. Journal of Affective Disorders 133, 625-632.

Maalouf FT, Klein C, Clark L, Sahakian BJ, Labarbara EJ, Versace A, Hassel S, Almeida JRC, Phillips ML (2010). Impaired sustained attention and executive dysfunction: bipolar disorder versus depression-specific markers of affective disorders. Neuropsychologia 48, 1862-1868.

Matthews K, Coghill D, Rhodes S (2008). Neuropsychological functioning in depressed adolescent girls. Journal of Affective Disorders 111, 113-118.

McCall W, Dunn A (2003). Cognitive deficits are associated with functional impairment in severely depressed patients. Psychiatry Research 121, 179-184.

McDermott LM, Ebmeier KP (2009). A meta-analysis of depression severity and cognitive function. Journal of Affective Disorders 119, 1-8.

Michopoulos I, Zervas IM, Pantelis C, Tsaltas E, Papakosta V-M, Boufidou F, Nikolaou C, Papageorgiou C, Soldatos CR, Lykouras L (2008). Neuropsychological and hypothalamic-pituitary-axis function in female patients with melancholic and non-melancholic depression. European Archives of Psychiatry and Clinical Neuroscience 258, 217-225.

Michopoulos I, Zervas IM, Papakosta VM, Tsaltas E, Papageorgiou C, Manessi T, Papakostas YG, Lykouras L, Soldatos CR (2006). Set shifting deficits in melancholic vs. non-melancholic depression: preliminary findings. European Psychiatry 21, 361-363.

Montgomery SA, Asberg M (1979). A new depression scale designed to be sensitive to change. British Journal of Psychiatry 134, 382-389. 
Mur M, Portella MJ, Martinez-Aran A, Pifarre J, Vieta E (2009). Influence of clinical and neuropsychological variables on the psychosocial and occupational outcome of remitted bipolar patients. Psychopathology 42, 148-156.

Murphy FC, Michael A, Robbins TW, Sahakian BJ (2003). Neuropsychological impairment in patients with major depressive disorder: the effects of feedback on task performance. Psychological Medicine 33, 455-467.

O'Brien JT, Lloyd A, McKeith I, Gholkar A, Ferrier IN (2004). A longitudinal study of hippocampal volume, cortisol levels, and cognition in older depressed subjects. American Journal of Psychiatry 161, 2081-2090.

Owen AM, Downes JJ, Sahakian BJ, Polkey CE, Robbins TW (1990). Planning and spatial working memory following frontal lobe lesions in man. Neuropsychologia 28, 1021-1034.

Owen AM, Sahakian BJ, Semple J, Polkey CE, Robbins TW (1995). Visuo-spatial short-term recognition memory and learning after temporal lobe excisions, frontal lobe excisions or amygdalo-hippocampectomy in man. Neuropsychologia 33, 1-24.

Porter RJ, Gallagher P, Thompson JM, Young AH (2003). Neurocognitive impairment in drug-free patients with major depressive disorder. British Journal of Psychiatry 182, 214-220.

Potter GG, Kittinger JD, Wagner HR, Steffens DC, Krishnan KRR (2004). Prefrontal neuropsychological predictors of treatment remission in late-life depression. Neuropsychopharmacology 29, 2266-2271.

Poznanski EO, Cook SC, Carroll BJ (1979). A depression rating scale for children. Pediatrics 64, 442-450.

Purcell R, Maruff P, Kyrios M, Pantelis C (1997). Neuropsychological function in young patients with unipolar major depression. Psychological Medicine 27, 1277-1285.

Reppermund S, Ising M, Lucae S, Zihl J (2009). Cognitive impairment in unipolar depression is persistent and non-specific: further evidence for the final common pathway disorder hypothesis. Psychological Medicine 39, 603-614.

RevMan (2011). Review Manager (RevMan), Version 5.1. The Nordic Cochrane Centre, The Cochrane Collaboration: Copenhagen.

Robbins TW, James M, Owen AM, Sahakian BJ, McInes L, Rabbitt PMA (1994). Cambridge Neuropsychological Test Automated Battery (CANTAB): a factor analytic study of a large sample of normal elderly volunteers. Dementia $\mathbf{5}$, 266-281.

Rogers RD, Blackshaw AJ, Middleton HC, Matthews K, Hawtin K, Crowley C, Hopwood A, Wallace C, Deakin JFW, Sahakian BJ, Robbins TW (1999). Tryptophan depletion impairs stimulus-reward learning while methylphenidate disrupts attentional control in healthy young adults: implications for the monoaminergic. Psychopharmacology 146, 482-491.

Roiser JP, Elliott R, Sahakian BJ (2012). Cognitive mechanisms of treatment in depression. Neuropsychopharmacology 37, 117-136.
Sahakian BJ, Jones G, Levy R, Gray J, Warburton DM (1989). The effects of nicotine on attention, information processing, and short-term memory in patients with dementia of the Alzheimer type. British Journal of Psychiatry 154, 797-800.

Sahakian BJ, Morris RG, Evenden JL, Heald A, Levy R, Philpot M, Robbins TW (1988). A comparative study of visuospatial memory and learning in Alzheimer-type dementia and Parkinson's disease. Brain 111, 695-718.

Sahakian BJ, Owen AM, Morant NJ, Eagger SA, Boddington S, Crayton L, Crockford HA, Crooks M, Hill K, Levy R (1993). Further analysis of the cognitive effects of tetrahydroaminoacridine (THA) in Alzheimer's disease: assessment of attentional and mnemonic function using CANTAB. Psychopharmacology 110, 395-401.

Snyder HR (2013). Major depressive disorder is associated with broad impairments on neuropsychological measures of executive function: a meta-analysis and review. Psychological Bulletin 139, 81-132.

Solé B, Bonnin C, Torrent C, Balanzá-Martinez V, Tabarés-Seisdedos R, Popovic D, Martinez-Arán A, Vieta E (2012). Neurocognitive impairment and psychosocial functioning in bipolar II disorder. Acta Psychiatrica Scandinavica 125, 309-317.

Stefanopoulou E, Manoharan A, Landau S, Geddes JR, Goodwin G, Frangou S (2009). Cognitive functioning in patients with affective disorders and schizophrenia: a meta-analysis. International Review of Psychiatry 21, 336-356.

Story TJ, Potter GG, Attix DK, Welsh-Bohmer KA, Steffens DC (2008). Neurocognitive correlates of response to treatment in late-life depression. American Journal of Geriatric Psychiatry 16, 752-759.

Swainson R, Hodges JR, Galton CJ, Paykel ES, Semple J, Michael A, Dunn BD, Iddon JL, Robbins TW, Sahakian BJ (2001). Early detection and differential diagnosis of Alzheimer's disease and depression with neuropsychological tasks. Dementia and Geriatric Cognitive Disorders 12, 265-280.

Sweeney JA, Kmiec JA, Kupfer DJ (2000). Neuropsychologic impairments in bipolar and unipolar mood disorders on the CANTAB neurocognitive battery. Biological Psychiatry 48, 674-684.

Taylor Tavares JV, Clark L, Cannon DM, Erickson K, Drevets WC, Sahakian BJ (2007). Distinct profiles of neurocognitive function in unmedicated unipolar depression and bipolar II depression. Biological Psychiatry 62, 917-924.

Tsaltas E, Kalogerakou S, Papakosta V-M, Kontis D, Theochari E, Koutroumpi M, Anyfandi E, Michopoulos I, Poulopoulou C, Papadimitriou G, Oulis P (2010). Contrasting patterns of deficits in visuospatial memory and executive function in patients with major depression with and without ECT referral. Psychological Medicine 41, 983-995.

Veiel HO (1997). A preliminary profile of neuropsychological deficits associated with major depression. 
Journal of Clinical and Experimental Neuropsychology 19, 587-603.

Weiland-Fiedler P, Erickson K, Waldeck T, Luckenbaugh DA, Pike D, Bonne O, Charney DS, Neumeister A (2004). Evidence for continuing neuropsychological impairments in depression. Journal of Affective Disorders 82, 253-258.

Weissman MM, Bland RC, Canino GJ, Faravelli C, Greenwald S, Hwu H, Joyce PR, Karam EG, Lee C,
Lellouch J, Newman SC, Rubio-Stipec M, Wells JE, Wickramaratne PJ, Wittchen H, Yeh E (2010).

Cross-national epidemiology of major depression and bipolar disorder. Journal of the American Medical Association 276, 293-299.

Zakzanis KK, Leach L, Kaplan E (1998). On the nature and pattern of neurocognitive function in major depressive disorder. Neuropsychiatry, Neuropsychology, and Behavioral Neurology 11, 111-119. 